\title{
Childhood energy intake and adult mortality from cancer: the Boyd Orr cohort study
}

\author{
Stephen Frankel, David J Gunnell, Tim J Peters, Maria Maynard, George Davey Smith
}

\begin{abstract}
Objective: To examine the relation between energy intake in childhood and adult mortality from cancer. Study design: Cohort study.

Setting: 16 rural and urban centres in England and Scotland.

Subjects: 3834 people who took part in Lord Boyd Orr's Carnegie survey of family diet and health in prewar Britain between 1937 and 1939 who were followed up with the NHS central register.

Standardised methods were used to measure household dietary intake during a one week period. Main outcome measures: Cancer mortality.

Results: Significant associations between childhood energy intake and cancer mortality were seen when the confounding effects of social variables were taken into account in proportional hazards models (relative hazard for all cancer mortality 1.15 (95\% confidence interval 1.06 to 1.24 ), $\mathrm{P}=0.001$, for every $\mathrm{MJ}$ increase in adult equivalent daily intake in fully adjusted models). This effect was essentially limited to cancers not related to smoking (relative hazard 1.20; 1.07 to 1.34; $\mathrm{P}=0.001$ ), with similar effects seen in men and women.

Conclusion: This positive association between childhood energy intake and later cancer is consistent with animal evidence linking energy restriction with reduced incidence of cancer and the association between height and human cancer, implying that higher levels of energy intake in childhood increase the risk of later development of cancer. This evidence for long term effects of early diet confirm the importance of optimal nutrition in childhood and suggest that the unfavourable trends seen in the incidence of some cancers may have their origins in early life.
\end{abstract}

\section{Introduction}

Interest in the relation between underfeeding and reduced mortality from cancer is long standing. ${ }^{\text {I It was }}$ shown some 60 years ago that energy restriction in an otherwise adequate diet extended life expectancy in rats considerably, ${ }^{2}$ and the animal evidence for a positive relation between dietary intake during the growth period and later incidence of cancer is now well established. ${ }^{3}$ Energy restriction limited to very early life has been shown to result in reduced risk of cancer, ${ }^{4}$ and delays in both onset and progression of cancer have been found..$^{5}$

Most of the human evidence concerning possible relations between nutrition and cancer comes from the use of body size as a proxy for dietary intake. This evidence has been accumulating since the early part of this century, ${ }^{6}$ with positive associations between height and some cancers being seen. For example, a positive relation between height and the risk of a wide variety of cancers was found in the 12554 subjects examined in the first national health and nutrition examination survey. ${ }^{7}$ The association with leg length was greater than that with overall height, a finding that is consistent with analyses from the Boyd Orr cohort. ${ }^{8}$ This finding is important as leg length is the component of overall height that is more susceptible to factors in childhood that influence growth. ${ }^{9}{ }^{10}$ In an international ecological study encompassing 24 populations, strong positive relations between height and a wide variety of cancers were seen, independent of weight. ${ }^{11}$ Similar findings were described in relation to colorectal cancer when the association with body mass index was weak and not significant, but the positive height association was strong. ${ }^{12}$ Positive geographical associations within England and Wales have been described for a number of cancers. ${ }^{13}$ Associations between height and mortality, however, are confounded by a range of socioeconomic factors that themselves have strong associations with mortality. ${ }^{14}$ The existence of other studies that do not replicate these height-cancer associations ${ }^{15}$ may therefore reflect the inadequacies of height as a proxy for childhood nutritional status and inadequate control for confounding, rather than the lack of an underlying relation between energy intake in childhood and later cancer.

Several types of cancer are more common in overweight people-for example, colorectal cancer is positively associated with body mass index, ${ }^{16}$ although the association may be weak. ${ }^{12}$ Few studies present data covering exposure in early life and later cancer. In general, reported associations between weight and cancer are even less consistent than those with height, as would be expected as body weight may be responsive to several influences, including dietary intake, exercise, pre-existing disease, and smoking, which have conflicting effects on incidence of cancer. ${ }^{77}$

Adult anthropometry is therefore an imperfect means for investigating the later effects of childhood
Department of Social Medicine, University of Bristol, Bristol BS8 2PR

Stephen Frankel, professor of epidemiology and public health medicine David J Gunnell, senior lecturer in epidemiology and public health medicine Tim J Peters, reader in medical statistics

Maria Maynard, research student George Davey Smith,

professor of clinical epidemiology

Correspondence to: Professor Frankel stephen.frankel.@ bristol.ac.uk

BMJ 1998;316:499-504 
nutrition. Data suitable for examining these relations directly are largely limited to asking subjects to recall childhood diet ${ }^{18-20}$ or assessing dietary change indirectly from broad national trends. For example, the reduced incidence of breast cancer in women who experienced puberty during the second world war has been attributed to the general reduction in dietary intake that occurred at that time. ${ }^{21}$ In the only human trial of energy restriction that has been published, the mortality and hospital admission rates of 60 elderly people subjected to dietary restriction were lower than those for a group of 60 elderly people on a more generous diet. ${ }^{22}$ In addition, there is ecological evidence from Japan associating low energy intake, small stature, and healthy longevity. ${ }^{23}$ In contrast with the uses of ecological, historical, or recall methods we used data on dietary intake collected during the late 1930 s in a national study of nutrition and health combined with follow up on mortality over about 50 years to examine the relation between childhood diet and adult disease.

\section{Methods}

The methods used to establish the Boyd Orr cohort have been described elsewhere. ${ }^{24}$ In short, the material used for this analysis is drawn from the original records of the Carnegie survey of family diet and health in prewar Britain. The survey was carried out on 1352 families in 16 rural and urban centres in England and Scotland over a 2 year period between 1937 and 1939. In all but two of the survey centres the children from the families underwent detailed physical examination.

Standardised methods were used to weigh and record the food available for the entire family at the beginning of one week. Every purchase of food during the survey week was also recorded and another inventory of all food in the home was made at the end of the week. In addition, the number of meals consumed outside the home and the weight and composition of household refuse were recorded during the week. A note was also made of which family members were present for each meal. Members of the dietary survey team regularly visited participating families to monitor progress with the dietary diaries and to encourage full recording of food bought and consumed during the week of study. Dietary information was subsequently summarised on separate recording sheets and analysed at the Rowett Research Institute to produce figures for per capita energy consumption by using contemporary food tables.

\section{Follow up}

We used the NHS central register to trace children whose families took part in the survey. Survey members who were resident in Britain on 1 January 1948 were included in the mortality analyses, which were based on deaths occurring up to 30 June 1996. Only survey members aged 16 years and under at the time of the survey were included in this analysis $(\mathrm{n}=4744)$. The numbers of children in each one year age band were about equal. Of the total sample, 713 were not traced, leaving a final sample of 4031. Data were missing for food expenditure (44), date of death (2), social class (41), survey date (3), and Townsend score (111). Observations with missing values were excluded, and full analyses were performed on 3834 (1895 male, 1939 female).

\section{Statistical methods}

Individual nutrient intakes were derived from the family intake by applying the weights proposed by the BMA's committee of nutrition. ${ }^{25}$ Per capita food expenditure, expressed in new pence, was derived by using the same weights. Cause of death was coded according to ICD-9 (international classification of diseases, ninth revision). We classified the following as smoking related cancers: lip (ICD-9 140); tongue (141); mouth and pharynx (143-9); oesophagus (150); pancreas (157); respiratory tract (160-163); and urinary tract (188-189). Cancers not related to smoking comprise all other malignant cancers (140-209, excluding those listed above). Tests for the associations between potentially confounding variables and energy intake were performed by entering energy intake as a continuous outcome variable into $t$ tests for the dichotomous variables (upper social class) and into linear regression models for the remaining variables, with the confounder entered as the exposure variable. Tests for trend for crude death rates across fifths of the distribution of energy intake were performed by entering energy intake as a continuous variable into Cox proportional hazards models for each outcome of interest. Deviation from linear trend was examined by likelihood ratio tests comparing the model with energy intake fifths entered as four dummy variables with the model where energy fifth was entered as a linear term. In addition, departures from linearity were investigated by using polynomial terms for energy intake as a continuous variable.

The association between energy intake in childhood and later mortality was examined in both sexes and in men and women separately, with adjustment for age at the time of the survey, household food expenditure, social class, and number of siblings. The Townsend deprivation score was also entered into these models to adjust for level of deprivation for the area of current residence or area of residence at the time of emigration or death. This index is based on car ownership, unemployment, overcrowded housing, and housing tenure (a lower score implies relative affluence). ${ }^{26}$ Time from survey was also entered into these models to allow for the fact that the survey was conducted over a 2 year period, with the result that age at time of survey will underestimate the age effect on mortality of those examined at the end of the survey. Social class was entered into these models as a categorical variable with six values: I and II; III (the distinction between manual and non-manual was not introduced until 1951); IV; V; unemployed; and unclassifiable. Confounding variables were entered into these models regardless of their individual associations with energy intake. Proportional hazards models were stratified for sex and district of residence at the time of the original survey. It is possible that in times of scarcity differential allocation of food within families may occur. To assess the possible impact of this potential bias of using energy intakes weighted for age, the models were repeated with energy intakes that took no account of the individual family member's age. Analyses were performed in Stata. ${ }^{27}$ 
Table 1 General categories of deaths from cancer (ICD-9 codes) for men and women. Values are numbers of cases

\begin{tabular}{lrr} 
Cancer & $\begin{array}{c}\text { Men } \\
(\mathbf{n = 1 8 9 5 )}\end{array}$ & $\begin{array}{c}\text { Women } \\
(\mathbf{n}=\mathbf{1 9 3 9})\end{array}$ \\
\hline Cancers not related to smoking: & 15 & 17 \\
\hline Gastrointestinal, including liver (151-156) & 0 & 26 \\
\hline Breast (174) & NA & 7 \\
\hline Cervix and uterus (180-183) & 4 & NA \\
\hline Prostate (185) & 5 & 3 \\
\hline Brain and central nervous system (191-192) & 9 & 6 \\
\hline Disseminated and unspecified (199) & 2 & 6 \\
\hline Lymphatic and haematopoietic tissue (200-208) & 4 & 1 \\
\hline Miscellaneous (142, 164, 170-172) & 5 & \\
\hline Cancers related to smoking: & 5 & 1 \\
\hline Mouth and pharynx (143-149) & 3 & 4 \\
\hline Oesophagus (150) & 46 & 22 \\
\hline Pancreas (157) & 5 & 4 \\
\hline Respiratory tract (160-163) & 103 & 100 \\
\hline Urinary tract (188-189)
\end{tabular}

$\mathrm{NA}=$ not applicable.

\section{Results}

The numbers of deaths from different cancers are shown in table 1 . The mean (SD) weighted energy intake was 12.2 (2.7) $\mathrm{MJ}$ /day. Energy intake varied as expected with a range of social variables. In particular there were clear and significant trends of increasing childhood energy intake with high social class, high household expenditure, and low number of children in the household (table 2). These differences were sustained into adulthood as expressed in a similarly significant trend with the Townsend score representing the level of social deprivation for the area of current residence or area of residence at time of emigration or death.

Crude death rates did not differ between fifths of energy intake for all cause mortality or cancer mortality for men (table 3) or women (table 4). For deaths not caused by cancer the linear trend for crude death rates was significant only for women, where those with lower energy intake in childhood experienced a higher mortality from causes other than cancer in adulthood. Age adjusted hazard ratios for the effect of energy intake on mortality outcomes similarly showed no effects in both sexes combined or in either sex (table 5). When the confounding effects of the social variables detailed in table 2 were entered into these models, however, significant associations between childhood energy intake and mortality were apparent. Hazard ratios were raised in relation to cancer mortality (hazard ratio 1.15 for every $\mathrm{MJ}$ increase in daily adult equivalent energy intake; $95 \%$ confidence interval 1.06 to $1.24 ; \mathrm{P}=0.001$ ), with similar effects seen in men and women. This effect, however, was attributable largely to cancers not related to smoking, where the hazard ratio for both sexes combined was 1.20 ( 1.07 to $1.34 ; \mathrm{P}=0.001)$. Hazard ratios in the age adjusted models for the whole sample, including cases with missing values for confounding variables, were similar to the hazard ratios reported in table 5 for the age adjusted models where cases with missing values had been excluded.

There were no significant interactions between sex and energy intake in their relations with mortality. Among women the association between energy intake

Table 2 Characteristics of each fifth of distribution of energy intake, 1 being lowest. Figures are means (SD) unless stated otherwise

\begin{tabular}{|c|c|c|c|c|c|c|}
\hline \multirow[b]{2}{*}{ Detail } & \multicolumn{5}{|c|}{ Fifth of distribution } & \multirow[b]{2}{*}{$P$ value } \\
\hline & 1 & 2 & 3 & 4 & 5 & \\
\hline Age (years) at survey & $6.8(4.6)$ & $6.3(4.4)$ & $6.7(4.6)$ & $6.5(4.4)$ & $6.8(4.5)$ & 0.9 \\
\hline No in upper social classes (I-III) & $236(31)$ & $259(34)$ & $364(48)$ & $416(53)$ & $517(68)$ & $<0.0001$ \\
\hline Household expenditure ${ }^{\star}$ & $22.5(5.9)$ & $27.6(6.9)$ & $32.3(8.4)$ & $35.0(9.7)$ & $43.6(12.6)$ & $<0.0001$ \\
\hline No of children in household & $4.9(2.0)$ & $4.6(1.8)$ & $4.4(1.9)$ & $4.2(1.8)$ & $3.7(1.7)$ & $<0.0001$ \\
\hline Townsend score $\dagger$ & $0.51(4.8)$ & $0.71(5.0)$ & $0.50(4.4)$ & $0.15(4.2)$ & $-0.18(3.5)$ & $<0.0001$ \\
\hline
\end{tabular}

${ }^{*}$ Recorded at time of survey and expressed in new pence per person per week (converted from originally recorded pounds, shillings, and pence).

tSee text for details.

Table 3 Crude death rates per 1000 person years (95\% confidence intervals) in men in each fifth of distribution of energy intake, 1 being lowest

\begin{tabular}{|c|c|c|c|c|c|c|}
\hline \multirow[b]{2}{*}{ Cause of death } & \multicolumn{5}{|c|}{ Fifth of distribution } & \multirow[b]{2}{*}{$P$ value } \\
\hline & 1 & 2 & 3 & 4 & 5 & \\
\hline All causes $(n=373)$ & 3.8 (3.0 to 4.7$)$ & $3.1(2.4$ to 4.7$)$ & 4.5 (3.7 to 5.5$)$ & 3.5 (2.8 to 4.4$)$ & $3.6(2.9$ to 4.4$)$ & 0.63 \\
\hline Cancers not related to smoking $(n=39)$ & $0.3(0.2$ to 0.7$)$ & $0.3(0.2$ to 0.7$)$ & $0.4(0.2$ to 0.8$)$ & $0.4(0.2$ to 0.8$)$ & $0.3(0.2$ to 0.7$)$ & 0.66 \\
\hline Cancers related to smoking $(n=64)$ & $0.6(0.3$ to 1.0$)$ & $0.5(0.3$ to 0.9$)$ & $0.9(0.6$ to 1.4$)$ & $0.4(0.2$ to 0.7$)$ & $0.7(0.4$ to 1.2$)$ & 0.78 \\
\hline Causes other than cancer $(n=270)$ & 2.9 (2.3 to 3.7$)$ & $2.3(1.7$ to 3.0$)$ & $3.2(2.6$ to 4.0$)$ & 2.7 (2.1 to 3.5$)$ & 2.5 (1.9 to 3.2$)$ & 0.56 \\
\hline
\end{tabular}

Table 4 Crude death rates per 1000 person years (95\% confidence intervals) in women in each fifth of distribution of energy intake, 1 being lowest

Fifth of distribution

\begin{tabular}{|c|c|c|c|c|c|c|}
\hline Cause of death & 1 & 2 & 3 & 4 & 5 & $P$ value \\
\hline All causes $(n=243)$ & 2.6 (2.0 to 3.4 ) & 2.6 (2.0 to 3.4 ) & 2.1 (1.6 to 2.8 ) & 2.0 (1.5 to 2.7 ) & 1.9 (1.4 to 2.5$)$ & 0.13 \\
\hline All cancers $(n=100)$ & $0.9(0.6$ to 1.3$)$ & $1.0(0.7$ to 1.5$)$ & $0.8(0.5$ to 1.3$)$ & $0.8(0.5$ to 1.3$)$ & $1.0(0.7$ to1.6) & 0.48 \\
\hline Cancers not related to smoking $(n=66)$ & $0.5(0.3$ to 0.9$)$ & $0.8(0.5$ to 1.3$)$ & $0.4(0.2$ to 0.8$)$ & $0.6(0.3$ to 1.0$)$ & $0.8(0.5$ to1.3) & 0.17 \\
\hline Causes other than cancer $(n=143)$ & 1.7 (1.3 to 2.4$)$ & 1.6 (1.2 to 2.2$)$ & $1.3(0.9$ to 1.9$)$ & $1.2(0.8$ to 1.7$)$ & $0.8(0.5$ to 1.3$)$ & 0.01 \\
\hline
\end{tabular}


Table 5 Hazard ratios (95\% confidence intervals) from fully adjusted models of energy intake as continuous variable on mortality per $1 \mathrm{MJ} /$ day (239 kcal) adjusted for age, household expenditure, social class, number of children, time since survey, and Townsend score of district of last posting

\begin{tabular}{lll} 
Cause of death & Age adjusted models & Fully adjusted models \\
\hline Both sexes ( $\mathbf{n}=\mathbf{3 8 3 4})$ & & \\
\hline All causes & $0.99(0.96$ to 1.02$)$ & $1.04(0.99$ to 1.09$) ; P=0.11$ \\
\hline All cancers & $1.05(0.99$ to 1.11$)$ & $1.15(1.06$ to 1.24$) ; P=0.001$ \\
\hline Cancers not related to cancer & $1.07(0.99$ to 1.15$)$ & $1.20(1.07$ to 1.34$) ; P=0.001$ \\
\hline Cancers related to smoking & $1.02(0.94$ to 1.11$)$ & $1.09(0.96$ to 1.23$) ; P=0.18$ \\
\hline Causes other than cancer & $0.96(0.92$ to 1.0$)$ & $0.99(0.93$ to 1.05$) ; P=0.71$ \\
\hline Men ( $\mathbf{n}=\mathbf{1 8 9 5 )}$ & $0.99(0.95$ to 1.04$)$ & $1.03(0.97$ to 1.09$) ; P=0.33$ \\
\hline All causes & $1.04(0.96$ to 1.13$)$ & $1.13(1.01$ to 1.27$) ; P=0.03$ \\
\hline All cancers & $1.06(0.94$ to 1.20$)$ & $1.24(1.03$ to 1.49$) ; P=0.025$ \\
\hline Cancers not related to cancer & $1.03(0.93$ to 1.14$)$ & $1.08(0.93$ to 1.25$) ; P=0.31$ \\
\hline Cancers related to smoking & $0.98(0.93$ to 1.02$)$ & $0.99(0.93$ to 1.07$) ; P=0.87$ \\
\hline Causes other than cancer & & \\
\hline Women ( $\mathbf{n}=\mathbf{1 9 3 9 )}$ & $0.98(0.94$ to 1.03$)$ & $1.06(0.98$ to 1.14$) ; P=0.16$ \\
\hline All causes & $1.05(0.98$ to 1.13$)$ & $1.16(1.03$ to 1.30$) ; P=0.011$ \\
\hline All cancers & $1.08(0.99$ to 1.17$)$ & $1.18(1.03$ to 1.35$) ; P=0.015$ \\
\hline Cancers not related to cancer & $1.01(0.88$ to 1.16$)$ & $1.11(0.89$ to 1.39$) ; P=0.34$ \\
\hline Cancers related to smoking & $0.93(0.87$ to 1.0$)$ & $0.98(0.88$ to 1.09$) ; P=0.68$ \\
\hline Causes other than cancer & &
\end{tabular}

Table 6 Age specific mean energy intakes in MJ/day (kcal/day) according to fifth of distribution of energy intake, 1 being lowest

\begin{tabular}{lccccc}
\multirow{2}{*}{$\begin{array}{l}\text { Age group } \\
\text { (years) }\end{array}$} & $\mathbf{1}$ & $\mathbf{2}$ & $\mathbf{3}$ & $\mathbf{4}$ & \multicolumn{5}{c}{ Fifth of distribution } \\
\cline { 2 - 6 } & $\mathbf{1}$ & $3.23(772)$ & $3.64(872)$ & $4.05(968)$ & $4.75(1137)$ \\
\hline $1-3$ & $3.70(633)$ & $4.52(1081)$ & $5.10(1221)$ & $5.66(1355)$ & $6.65(1592)$ \\
\hline $4-9$ & $5.82(1393)$ & $7.10(1698)$ & $8.02(1919)$ & $8.90(2130)$ & $10.45(2501)$ \\
\hline $10-14$ & $7.59(1815)$ & $9.25(2213)$ & $10.45(2500)$ & $11.60(2775)$ & $13.62(3259)$ \\
\hline $15-20$ & $8.11(1941)$ & $9.89(2367)$ & $11.12(2674)$ & $12.41(2969)$ & $14.58(3487)$ \\
\hline Women $>20$ & $7.32(1751)$ & $8.93(2136)$ & $10.09(2413)$ & $11.19(2678)$ & $13.15(3146)$ \\
\hline Men $>20$ & $8.82(2110)$ & $10.76(2573)$ & $12.15(2907)$ & $13.49(3227)$ & $15.84(3790)$ \\
\hline
\end{tabular}

and cancer mortality was largely explained by increases in cancers other than breast cancer. The hazard ratio for energy intake on mortality from breast cancer was $1.10(0.89$ to $1.36 ; \mathrm{P}=0.40)$, while for all cancers other than breast cancer the hazard ratio was 1.21 ( 1.05 to $1.39 ; \mathrm{P}=0.008$ ). The effect of the weightings used to derive individual energy intake was examined by repeating these models with crude energy intakes. The effects remained, though they were slightly attenuated; for example, the hazard ratio for cancer not related to smoking, both sexes combined, in models where crude energy intake was entered was 1.15 (1.02 to $1.29 ; \mathrm{P}=0.028)$. The proportional hazards assumptions were found to be valid. Significant departures from linear trends in the proportional hazards models were not found; this is consistent with a broadly linear association between energy intake and risk of cancer across the range of energy intakes. Hazard ratios for each fifth of energy intake for cancer not related to smoking, both sexes combined, were as follows (lowest fifth of energy intake as reference): 2nd fifth 1.53 (0.81 to 2.89); 3rd fifth 1.19 (0.57 to 2.46); 4th fifth 1.74 (0.83 to 3.64); highest fifth 2.54 (1.07 to 6.03). Lack of significant departures from linearity were confirmed in polynomial (Cox) regression models with energy intake entered as a continuous variable. Hazard ratios for age adjusted models including the whole sample were similar to those where cases with missing values had been excluded.

\section{Discussion}

This historical cohort study based on over 50 years' follow up of 3834 subjects whose family dietary intake was measured during childhood shows a positive association between energy intake during early life and later mortality from cancers other than those related to smoking. An increased energy intake of $1 \mathrm{MJ}$ /day was associated with a $20 \%$ increased risk of mortality from such cancer after adjustment for potentially confounding effects of household expenditure, social class, number of children, and Townsend deprivation score. Energy intake is here expressed in terms of adult equivalent levels. Intakes of individual subjects will clearly have differed according to age. The equivalent mean intakes for each age group and fifth of energy consumption that can be derived from recorded family intakes and the age specific intakes expressed in the BMA weightings ${ }^{25}$ are shown in table 6 . The age specific values in the 3rd fifth are similar to those quoted in the Department of Health's 1991 diet reference values for food publication ${ }^{28}$-for example, for 4-6 year olds in MJ (kcal): 7.17 (1715) for boys and 6.46 (1545) for girls; 7-10 year olds 8.23 (1970) and 7.27 (1740); and 15-18 year olds 11.52 (2755) and 8.82 (2110).

\section{Possible biases}

Several aspects of the data and analysis must be considered before the suggestion of any causative relation between energy intake in childhood and adult cancer. The main deficiency of this study is that individual childhood nutritional intake has been derived from grouped family data. It is well known that individual intakes, especially of children, may differ markedly from the overall family diet. This problem would be more relevant, however, if we were concerned with the importance of specific dietary constituents, particularly of vitamins and trace elements. Here we were concerned primarily with relatively gross differences in overall energy consumption, and the weighted intake is more likely to reflect an individual child's experience. The possibility of bias arising from the weightings used in deriving estimates of individual intakes must be considered. This is not an important consideration, however, as the key associations remained when the effects of crude individual energy intakes were examined; that these effects were somewhat attenuated in relation to the weighted measures is to be expected as the crude intake values necessarily represent less precise measures of exposure.

Data were missing for a number of the social variables, and selection bias must therefore be considered as an explanation for the associations that emerged in the multivariable models where these individuals were excluded. The similarity in hazard ratios between the age adjusted models for the whole sample and the models where cases with missing values had been excluded, however, makes this bias unlikely.

The association was not seen when models were unadjusted for social and economic variables but emerged in the models adjusted for the range of social and economic variables available. This result is to be expected when the association between a childhood exposure and later disease is strongly confounded by socioeconomic status. Here, those with more deprived 
childhoods had in general lower energy intake and higher subsequent mortality; only when these opposing influences were separated by adjustment could any association between individual childhood energy intake and later mortality be examined. A similar trend was seen in the Whitehall study, in which the positive association between height and mortality from malignant neoplasms emerged only after adjustment for employment grade. ${ }^{14}$ The limited ability of multivariable methods to control for confounding ${ }^{29}$ means that the true association is likely to be stronger than that found here.

The case that the association seen here is not to be explained by bias or confounding is strengthened by its specificity. The effect of childhood energy intake on later mortality from cancer was seen only for cancers not related to smoking. One would expect no strong association between childhood energy intake and cancers ascribable to smoking as the deleterious effects of tobacco would probably mask any effects of diet, and adult smoking shows no independent association with childhood social class in a study based on a cohort growing up at this same time period. ${ }^{30}$

\section{Influence of method of assessment of nutrition in childhood}

We know of no other study based on the long term follow up of a cohort for which dietary intake was collected at the outset. The fundamental limitations to other human studies in this area stem from the use of dietary information that is ecological or gathered by recall or from the use of adult anthropometry as a proxy for early nutrition. There are three main problems with use of height as a proxy for childhood nutrition. Firstly, the effects of dietary restriction in animal models can be found in the absence of growth retardation. ${ }^{31}{ }^{32}$ Secondly, there seems to be a threshold effect in the relation between height and some aspects of risk of cancer. ${ }^{7}$ The association between stature and breast cancer found in black women in the United States $^{33}$ is consistent with there being a stronger height-disease relation in populations where achieved height may be influenced more by relative nutritional deprivation than by genetic potential. Similarly in a study of 23831 Norwegian women the positive association between breast cancer and height was stronger among the younger women. ${ }^{34}$ These women had experienced their stage of maximum adolescent growth during the war years, when there was much greater nutritional diversity, including considerable undernutrition. It may not be possible to study an association between energy intake as expressed in achieved height and later cancer when nutritional intake is sufficient for all subjects to grow to their genetic potential. Thirdly, both height and later cancer may be subject to influence by infection-for example, by Helicobacter pylori.

The association between childhood diet and later cancer was seen in relation to overall energy intake. This is consistent with animal evidence, where energy restriction, rather than individual component restriction without energy restriction, is the key intervention delaying death from neoplastic disease. ${ }^{35}$ The evidence presented here suggests that the effect on incidence of cancer operates within the normal range of energy intakes. This is also consistent with the
- Animal studies have shown that energy restriction results in a reduced risk of cancer. Some cancers are more common in taller people, suggesting that the same effect may be important in humans

- The association between diet in childhood and later cancer was examined on the basis of detailed dietary data collected from a cohort of children in the late 1930s

- A positive association emerged between childhood energy intake and later cancer (other than cancer related to smoking), once adjustment for socioeconomic variables had been made

- This evidence for long term effects of early diet confirms the importance of optimal childhood nutrition by implying that higher levels of energy intake in childhood increase the risk of the later development of cancer

animal evidence, where positive effects on longevity and delayed onset of tumour are also found with moderate levels of dietary restriction. ${ }^{32}$

Various mechanisms have been suggested for the effects of dietary restriction on carcinogenesis. Dietary restriction also retards cell proliferation during development as well as cell renewal in most organs at later stages, thus potentially reducing the chance of genetic changes arising from carcinogens or active oxygen species. ${ }^{5}$ Other possible mechanisms include more vigorous immune responses in the dietary restricted organism and the reduced oncogene expression seen in energy restricted animals. ${ }^{36}{ }^{37}$

\section{Conclusions}

The association found here between childhood energy intake and later cancer is consistent with the animal evidence that energy restriction reduces mortality from cancer and the association between height and human cancer. These findings imply that higher levels of energy intake in childhood increase the risk of the later development of cancer. It will be important to collect morbidity and mortality data from other cohorts for which data on childhood diet were gathered. If these findings are replicated in such cohorts the public health implications with respect to optimal childhood nutrition, particularly in the context of current concerns about excess childhood intake in relation to exercise levels, ${ }^{38}$ will be profound.

Contributors: The Boyd Orr cohort was established by GDS and SF. DJG further developed and refined the cohort. Statistical and nutritional input came from TJP and MM, respectively. The analyses were performed by SF, who wrote the first draft and subsequently incorporated the ideas of DJG, TJP, MM, and GDS. SF, DJG, and GDS are guarantors of the study.

Funding: Medical Research Council; British Heart Foundation; World Cancer Research Fund.

Conflict of interest: None.

1 Rous P. The influence of diet on transplanted and spontaneous mouse tumors. J Exp Med 1914;20:433-51.

2 McCay CM, Crowell MF, Maynard LA. The effect of retarded growth upon the length of life span and upon the ultimate body size. J Nutr 1935; 10:63-79.

3 Kristal BS, Yu BP. Aging and its modulation by dietary restriction. In: Yu $\mathrm{BP}$, ed. Modulation of aging processes by dietary restriction. London: CRC Press, 1994:1-36.

4 Ross MH, Bras G. Lasting influence of early caloric restriction on prevalence of neoplasms in the rat. J Natl Cancer Inst 1971;47:1095-113.

5 Shimokawa I, Higami Y. Effect of dietary restriction on pathological processes. In: Yu BP, ed. Modulation of aging processes by dietary restriction. London: CRC Press, 1994:247-66. 
6 Tannenbaum A. Relationship of body weight to cancer incidence. Arch Pathol 1940;30:509-17.

7 Albanes D, Jones DY, Schatzkin A, Micozzi MS, Taylor PR. Adult stature and risk of cancer. Cancer Res 1988;48:1658-62.

8 Gunnell DJ, Davey Smith G, Frankel SJ, Nanchahal K, Braddon FEM, Peters TJ. Childhood leg length and adult mortality-follow up of the Carnegie survey of diet and growth in prewar Britain. J Epidemiol Community Health 1996;50:580-1. (Abstract.)

9 Gunnell DJ, Davey Smith G, Frankel SJ, Kemp M, Peters TJ. Socioeconomic and dietary influences on leg length and trunk length in childhood: a re-analysis of the Carnegie survey of diet and health in prewar Britain (1937-9). Paediatr Perinat Epidemiol (in press).

10 Tanner JM, Hayashi T, Preece MA, Cameron N. Increase in length of leg relative to trunk in Japanese children and adults from 1957 to 1977 comparison with British and with Japanese Americans. Ann Hum Biol 1982;9:411-23.

11 Albanes D, Taylor PR. International differences in body height and weight and their relationship to cancer incidence. Nutr Cancer 1990;14:69-77.

12 Chute CG, Willett WC, Colditz GA, Stampfer MJ, Baron JA, Rosner B, et al. A prospective study of body mass, height, and smoking on the risk of colorectal cancer in women. Cancer Causes Cont 1991;2:117-24.

13 Barker DJP, Osmond C, Golding J. Height and mortality in the counties of England and Wales. Ann Hum Biol 1990;17:1-6.

14 Leon D, Davey Smith G, Shipley M, Strachan D. Adult height and mortality in London: early life, socioeconomic confounding or shrinkage? J Epidemiol Community Health 1995;49:5-9.

15 Vatten LJ. Body size and breast cancer risk. The Breast 1996;5:5-9.

16 Kune GA, Kune S, Watson LF. Body weight and physical activity as predictors of colorectal cancer risk. Nutr Cancer 1990;13:9-17.

17 Thorling EB. Obesity, fat intake, energy balance, exercise and cancer risk. A review. Nutrition Res 1996;16:315-68.

18 Andersson S-O, Baron J, Wolk A, Lindgren C, Bergström R, Adami H-O. Early life risk factors for prostate cancer: a population-based case-control study in Sweden. Cancer Epidemiol Biomarkers Prev 1995;4:187-92.

19 Pryor M, Slattery ML, Robison LM, Egger M. Adolescent diet and breas cancer in Utah. Cancer Res 1989;49:2161-7.

20 Hislop TG, Coldman AJ, Elwood JM, Brauer G, Kan L. Childhood and recent eating patterns and risk of breast cancer. Cancer Detect Prev 1986;9:47-58

21 Tretli S, Gaard M. Lifestyle changes during adolescence and risk of breast cancer: an ecologic study of the effect of world war II in Norway. Cancer Causes Cont 1996;7:507-12.

22 Arias Vallejo E. La dieta de hambre a días alternos en la alimentación de los viejos. Revista Clínica Española 1956;63:25-7.
23 Kagawa Y. Impact of westernization on the nutrition of Japanese: changes in physique, cancer, longevity and centenarians. Preu Med 1978;7:205-17.

24 Gunnell DJ, Frankel S, Nanchahal K, Braddon FEM, Davey Smith G. Lifecourse exposure and later disease: a follow-up study based on a survey of family diet and health in pre-war Britain (1937-9). Public Health 1996;110:85-94.

25 British Medical Association. Report of committee on nutrition. London: BMA, 1933.

26 Phillimore P, Beattie A, Townsend P. Widening inequality of health in northern England, 1981-1991. BMJ 1994;308:1125-8.

27 StataCorp. Stats Statistical Software:release 5.0. College Station, Texas: Stata Corporation, 1996.

28 Department of Health. Dietary reference values for food energy and nutrient for the United Kingdom. 5th ed. London: HMSO, 1992.

29 Phillips AN, Davey Smith G. How independent are "independent" effects? Relative risk estimation when correlated exposures are measured imprecisely. J Clin Epidemiol 1991;44:1223-31.

30 Blane D, Hart CL, Davey Smith G, Gillis CR, Hole DJ, Hawthorne VM. Association of cardiovascular disease risk factors with socioeconomic position during childhood and during adulthood. BMJ 1996;313:1434-8

31 Yu BP, Masoro EJ, Murata I, Bertrand HA, Lynd FT. Life span study of SPF Fischer 344 male rats fed ad libitum or restricted diets: longevity, growth, lean body mass and disease. J Gerontol 1982;37:130-41.

32 Berg BN, Simms HS. Nutrition and longevity in the rat. II. Longevity and onset of disease with different levels of food intake. J Nutrition 1960;71:255-63.

33 Palmer JR, Rosenberg L, Harlap S, Strom BL, Warshauer MR, Zauber AG, et al. Adult height and risk of breast cancer among US black women. $A m$ J Epidemiol 1995;141:845-9.

34 Vatten LJ, Kvinnsland S. Body height and risk of breast cancer. A prospective study of 23,831 Norwegian women. $\mathrm{Br} J$ Cancer 1990;61:881-5.

35 Shimokawa I, Yu BP, Masoro EJ. Influence of diet on fatal neoplastic disease in male Fischer 344 rats. J Gerontol 1991;46:B228-32.

36 Kritchevsky D. The effect of over- and undernutrition on cancer. Eur J Cancer Prev 1995;4:445-51.

37 Weindruch R. Effect of caloric restriction on age-associated cancers. Exp Gerontol 1992;27:575-81.

38 Prentice AM, Jebb SA. Obesity in Britain: gluttony or sloth? BMJ 1995;311:437-9.

(Accepted 3 October 1997)
Mario Negri

Institute for

Pharmacological

Research, Clinical

Research Centre for

Rare Diseases, Via

Gavazzeni 11,

24125 Bergamo,

Italy

Piero Ruggenenti,

doctor

Flavio Gaspari,

chemist

Annalisa Perna,

statistical scientist

Giuseppe Remuzzi,

director

Correspondence to: Dr Ruggenenti

ruggenenti@irfmn.

mnegri.it

BMJ 1998;316:504-9

\begin{abstract}
Objective: To evaluate whether the protein:creatinine ratio in spot morning urine samples is a reliable indicator of 24 hour urinary protein excretion and predicts the rate of decline of glomerular filtration rate and progression to end stage renal failure in non-diabetic patients with chronic nephropathy.
\end{abstract}

Design: Cross sectional correlation between the ratio and urinary protein excretion rate. Univariate and multivariate analysis of baseline predictors, including the ratio and 24 hour urinary protein, of decline in glomerular filtration rate and end stage renal failure in the long term.

Setting: Research centre in Italy.

Subjects: 177 non-diabetic outpatients with chronic renal disease screened for participation in the ramipril efficacy in nephropathy study.

Main outcome measures: Rate of decline in filtration rate evaluated by repeated measurements of unlabelled iohexol plasma clearance and rate of progression to renal failure.

Results: Protein:creatinine ratio was significantly correlated with absolute and log transformed 24 hour urinary protein values $(\mathrm{P}=0.0001$ and $\mathrm{P}<0.0001$, respectively.) Ratios also had high predictive value for rate of decline of the glomerular filtration rate (univariate $\mathrm{P}=0.0003$, multivariate $\mathrm{P}=0.004$ ) and end stage renal failure $(\mathrm{P}=0.002$ and $\mathrm{P}=0.04)$. Baseline protein:creatinine ratios and rate of decline of the glomerular filtration rate were also significantly correlated $(\mathrm{P}<0.0005)$. In the lowest third of the protein:creatinine ratio $(<1.7)$ there was $3 \%$ renal failure compared with $21.2 \%$ in the highest third $(>2.7)(\mathrm{P}<0.05)$.

Conclusions: Protein:creatinine ratio in spot morning urine samples is a precise indicator of proteinuria and a reliable predictor of progression of disease in non-diabetic patients with chronic nephropathies and represents a simple and inexpensive procedure in establishing severity of renal disease and prognosis. 